\title{
RAPAPORT
}

\section{Resilience Assessment Process and Portfolio Option Reporting Tool}

\author{
Paul Dreyer
}

RAND Project AIR FORCE

Prepared for the United States Air Force

Approved for public release; distribution unlimited 
For more information on this publication, visit www.rand.org/t/TL184

Published by the RAND Corporation, Santa Monica, Calif.

(C) Copyright 2016 RAND Corporation

RAND $^{\circledR}$ is a registered trademark.

\section{Limited Print and Electronic Distribution Rights}

This document and trademark(s) contained herein are protected by law. This representation of RAND intellectual property is provided for noncommercial use only. Unauthorized posting of this publication online is prohibited. Permission is given to duplicate this document for personal use only, as long as it is unaltered and complete. Permission is required from RAND to reproduce, or reuse in another form, any of its research documents for commercial use. For information on reprint and linking permissions, please visit www.rand.org/pubs/permissions.html.

The RAND Corporation is a research organization that develops solutions to public policy challenges to help make communities throughout the world safer and more secure, healthier and more prosperous. RAND is nonprofit, nonpartisan, and committed to the public interest.

RAND's publications do not necessarily reflect the opinions of its research clients and sponsors.

\section{Support RAND}

Make a tax-deductible charitable contribution at

www.rand.org/giving/contribute

www.rand.org 


\section{Preface}

This document presents Chapter Four of a longer document:

- RAPAPORT (Resilience Assessment Process and Portfolio Option Reporting Tool): Background and Method, Paul Dreyer, Krista S. Langeland, David Manheim, Gary McLeod, and George Nacouzi, Santa Monica, Calif.: RAND Corporation, 2016, www.rand.org/t/RR1169.html

The longer document describes the development of the Resilience Assessment Process and Portfolio Option Reporting Tool (RAPAPORT). The chapter presented here is a user manual for the Portfolio Option Reporting Tool, and it is included as part of the tool, which is available at www.rand.org/t/TL184.

This research was sponsored by the commander, Air Force Space Command, and was conducted within the Force Modernization and Employment Program of RAND Project AIR FORCE as part of a fiscal year 2014 project, "Space Resilience: Developing a Strategy for Balancing Capability and Affordability with Resilience."

\section{RAND Project AIR FORCE}

RAND Project AIR FORCE (PAF), a division of the RAND Corporation, is the U.S. Air Force's federally funded research and development center for studies and analyses. PAF provides the Air Force with independent analyses of policy alternatives affecting the development, employment, combat readiness, and support of current and future air, space, and cyber forces. Research is conducted in four programs: Force Modernization and Employment; Manpower, Personnel, and Training; Resource Management; and Strategy and Doctrine. The research reported here was prepared under contract FA7014-06-C-0001.

Additional information about PAF is available on our website:

http://www.rand.org/paf 


\section{The Portfolio Option Reporting Tool}

\section{Introduction}

RAPAPORT is implemented as a workbook in Microsoft Excel with a Visual Basic back end to handle calculations and outputs. ${ }^{1}$ The capabilities of options against test cases of adverse events (in the tool denoted as Threats for compactness) can be represented either with numeric values or with the color of the cell (which maps back to a particular numeric value). Below, we describe how to set up a resilience assessment process inside the tool and the set of outputs available.

Input Sheets (red tabs)

\section{Start Page}

The Start Page sheet (Figure 4.1) appears when the workbook is opened. It contains contact information for the author, copyright information, and a PDF copy of this chapter of the document.

Figure 4.1. Welcome Sheet

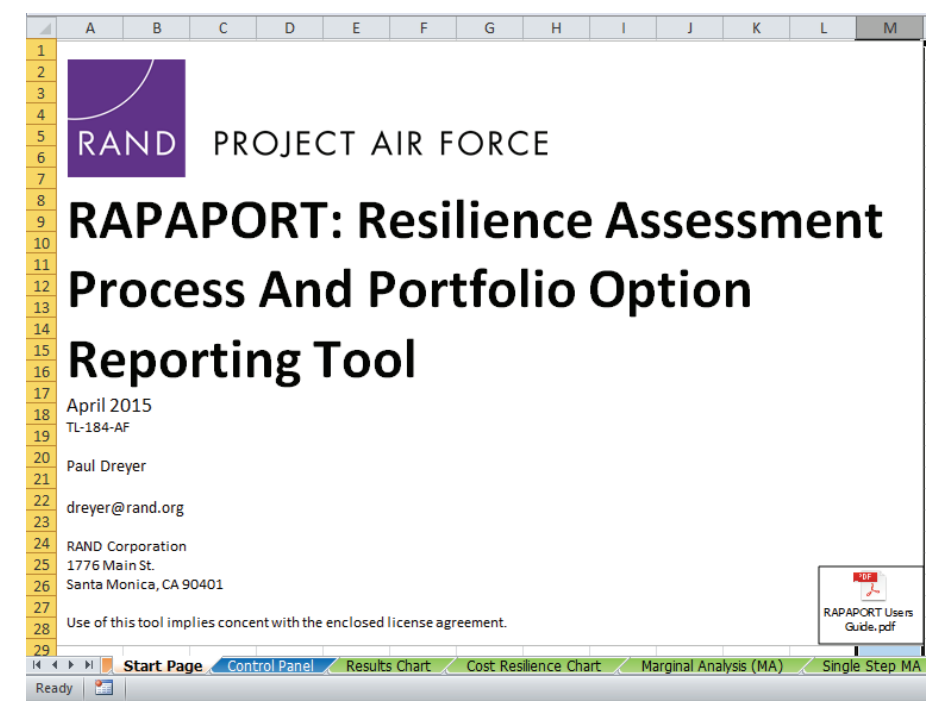

${ }^{1}$ RAPAPORT is available at www.rand.org/t/TL184. The tool has been tested in Microsoft Excel 2007 and 2010 for Windows and 2008 for Macs. 


\section{Control Panel}

The Control Panel sheet is actually both an input and output sheet, consisting of a series of tables for data entry and then the numeric results from the resilience calculations at the bottom of the sheet.

\section{Color Key}

The color key (Figure 4.2) is used throughout the workbook to denote levels of capability (Low, Low/Medium, Medium, Medium/High, and High). Unless a cell contains a number between 0 and 1 , the value associated to that entry corresponds to the color of the cell. If the cell has no fill (or has a white fill), it is assumed that the value is zero. If other cell colors are used in the assessment tables, the tool will announce an error. Using cell fill colors as the identifier of capability has the added bonus that text can be entered in the cells explaining how the level of capability was determined. If the user decides to use a different set of colors, there is a swap key in the first row in columns J through N. The user can put the desired colors in those cells, click on the Swap Colors button, and the desired colors will become the default colors and will be swapped throughout the entire workbook.

Figure 4.2. Color Key

\section{Color Key:}

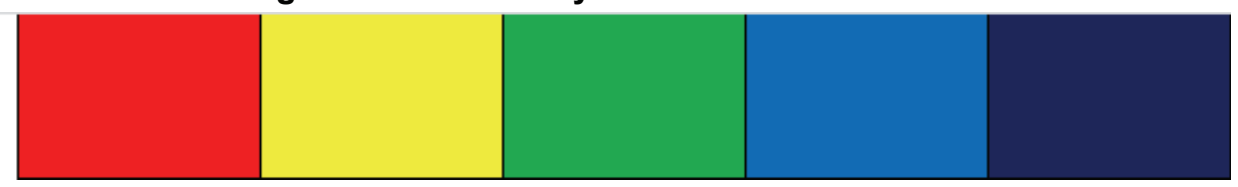

\section{Baseline and Option Weights}

There are two tables that define to what values the colors correspond. There are separate tables for the baseline and the option assessments. (An example Baseline Weights table is shown in Figure 4.3.) The value of a color can change from element to element.

Figure 4.3. Baseline Weights Table

\section{Baseline Weights}

Doctrine

Organization

Training

Personnel

Facilities

\begin{tabular}{|l|l|l|l|l|}
\hline & & & & \\
\hline 0.1 & 0.25 & 0.5 & 0.75 & 1 \\
\hline 0.1 & 0.25 & 0.5 & 0.75 & 1 \\
\hline 0.1 & 0.25 & 0.5 & 0.75 & 1 \\
\hline 0.1 & 0.25 & 0.5 & 0.75 & 1 \\
\hline 0.1 & 0.25 & 0.5 & 0.75 & 1 \\
\hline
\end{tabular}

\section{Link Weights and Linkages}

To calculate the influenced element resilience, it is necessary to enter the linkages between the various elements. Link weights are again color coded (using the same color scale as the baseline and option weights), although the values they represent may be different. Below, the link weights row is a table where linkages between influencing element and influenced element can be added. 
Each row consists of two element names, with a color in the third column representing the strength of the influence (the text shown in the colored cells in the example above is not necessary). As an example, in Figure 4.4, it is assessed that the doctrine, organization, training, materiel, leadership and education, personnel, facilities, and policy (DOTMLPF) element of Organization influences the element of Personnel at a Medium level and Facilities at a Medium/High level. Accordingly, a change in the resilience of the Organization element would result in a greater influence on Facilities than on Personnel.

Figure 4.4. Link Weights and Element Linkages Table

Link Weights

Linkages

Influencer

Doctrine

Organization

Organization

Organization

Training

Training

Personnel

Personnel

Personnel
0.01

0.05

0.1

0.25

\section{Posture Resilience Element Weights}

For each posture under consideration, a different weighting of (influenced) element resilience should be added to the right of the Weightings table as a new column. The entry at the bottom is calculated and will be red or green depending on whether the sum of the weights of the elements is 1 or not. A scatterplot of overall resilience versus cost is one of the output sheets, and the posture that should be shown in that scatterplot should be identified with an asterisk somewhere in the posture name. Also shown in Figure 4.5 is the Run Model button, which causes all of the resilience calculations to be performed.

Figure 4.5. Posture Resilience Element Weights Table

\begin{tabular}{l|c|c|}
\multirow{2}{*}{$\begin{array}{l}\text { Weightings } \\
\text { (*appears in scatterplot) }\end{array}$} & \multicolumn{2}{c}{ Run Model } \\
\cline { 3 - 3 } Doctrine & Day-to-Day & Crisis* \\
\cline { 2 - 3 } Organization & $\mathbf{2 5 \%}$ & $\mathbf{1 5 \%}$ \\
\cline { 2 - 3 } Training & $\mathbf{2 5 \%}$ & $\mathbf{1 0 \%}$ \\
\cline { 2 - 3 } Personnel & $\mathbf{0 \%}$ & $\mathbf{0 \%}$ \\
\hline Facilities & $\mathbf{2 5 \%}$ & $\mathbf{5 0 \%}$ \\
\hline Total & $\mathbf{2 5 \%}$ & $\mathbf{2 5 \%}$ \\
\cline { 2 - 3 } & $\mathbf{1 0 0 \%}$ & $\mathbf{1 0 0 \%}$ \\
\hline
\end{tabular}




\section{Cost and Portfolio Option Information}

The remainder of the inputs on this worksheet define the options and portfolio compositions (Figure 4.6). In the Options List, each row represents and option and has a description, which element it applies to, the cost and ease of implementation of the option. The cost can be a number, or Low, Medium, or High (or just the first letters, L/M/H). The Cost Category table above the options list gives a corresponding representative cost for each cost category. The Ease to Implement column also takes $\mathrm{L} / \mathrm{M} / \mathrm{H}$ values. Each portfolio should be represented as a column directly to the right of the four columns describing the options, with its name in the top row and its composition described by either 0 s and $1 \mathrm{~s}$ for each option row, depending on whether the option is contained in the portfolio or not. Note, for example, that the Everything portfolio contains all of the first three options, while the All Doctrine portfolio contains only the first two (not all options are shown). The Options Combo Rule above the Options List is either an M or a $\mathrm{P}$, representing $[\mathrm{M}]$ aximum or $[\mathrm{P}]$ roduct, corresponding to the most pessimistic or optimistic rule, respectively, for combining multiple options against the adverse events in a test case. Options and portfolios can be added or removed by adding or deleting rows (columns) as appropriate.

Figure 4.6. Cost Information, Options List, and Portfolio Composition Table

\begin{tabular}{|c|c|c|c|c|c|c|c|c|c|}
\hline Cost Category & $\begin{array}{l}\text { Representative } \\
\text { Cost (\$M) }\end{array}$ & & & \multirow[b]{5}{*}{ Portfolios } & \multirow[b]{7}{*}{ All Doctrine } & & & \multirow[b]{7}{*}{ All Personnel } & \multirow[b]{7}{*}{ All Facilitie } \\
\hline Low & \begin{tabular}{|l|}
0.05 \\
\end{tabular} & & & & & & & & \\
\hline Medium & 2 & & & & & & & & \\
\hline High & 5 & & & & & & & & \\
\hline Options Combo Rule & $\mathbf{P}$ & & & & & & & & \\
\hline Options List & & \multicolumn{2}{|c|}{$\begin{array}{c}\text { Enter numbers or Low } / \mathrm{Med} / \mathrm{High} \\
\text { Ease to }\end{array}$} & Include (0/1) & & & & & \\
\hline Description & Aspect & Cost & Implement & Everything & & All Organi & & & \\
\hline $\begin{array}{l}\text { Develop tactics for likely } \\
\text { counterspace threats in }\end{array}$ & Doctrine & L & M & 1 & 1 & 0 & 0 & 0 & 0 \\
\hline $\begin{array}{l}\text { Develop a more timely } \\
\text { anomaly resolution process }\end{array}$ & Doctrine & M & L & 1 & 1 & 0 & 0 & 0 & 0 \\
\hline $\begin{array}{l}\text { Transfer space order of } \\
\text { battle responsibilities from }\end{array}$ & Organization & H & M & 1 & 0 & 1 & 0 & 0 & 0 \\
\hline
\end{tabular}

\section{Threats Versus Impacts}

This table has two columns for each element and one row per test case of adverse events (Figure 4.7). For each test case and element, the weight corresponds to either the probability of the event or its relative importance to the decisionmaker. If a threat is added or removed, it must be removed from the Baseline and Option Assessment by Element sheets described below. The impact corresponds to the decrease of the system's capability (that is, the metric being computed for a given DOTMPLF element) if the events in the test case occur unimpeded (ignoring any potential resilience of the current system to the adverse events). Both values should be between 0 and 1 inclusive. The comments on the Impact columns contain the definitions of the metrics being calculated. 
Figure 4.7. Threats Versus Impacts Table

\begin{tabular}{|c|c|c|c|c|c|c|c|c|c|c|}
\hline \multirow{2}{*}{ THREATS Impacts } & \multicolumn{2}{|c|}{ Doctrine } & \multicolumn{2}{|c|}{ Organization } & \multicolumn{2}{|c|}{ Training } & \multicolumn{2}{|c|}{ Personnel } & \multicolumn{2}{|c|}{ Facilities } \\
\hline & Weight & Impact & Weight & Impact & Weight & Impact & Weight & Impact & Weight & Impac \\
\hline ASAT attack & 1 & 1 & 1 & 1 & 1 & 1 & 1 & 1 & 1 & 1 \\
\hline jamming uplink & 1 & 1 & 1 & 1 & 1 & 1 & 1 & 1 & 1 & 1 \\
\hline blinding laser/dazzling attack & 1 & 1 & 1 & 1 & 1 & 1 & 1 & 1 & 1 & 1 \\
\hline
\end{tabular}

Baseline and Option Assessment by Element (Doctrine, Organization, Training, Personnel, and Facilities Sheets)

There are five input worksheets corresponding to the DOTMLPF-P elements under consideration. The Doctrine sheet is shown in Figure 4.8. On each sheet, all of the threats from the Threats Versus Impacts table must be listed in the same order as rows in the tables on these sheets, while the columns correspond to the options specific to that element. If options are added or removed from the model, the corresponding columns must also be removed from these worksheets. The first column corresponds to the baseline capability of the system against each adverse event, while the names in the column headings must match those in the Options List on the Control Panel sheet exactly. The values in the table correspond to the expected amount of lost capability the current system (or an option) can recover against a particular adverse event. The cell colors in the table can be one of the five in the color key or left unfilled (corresponding to a value of zero). Alternatively, if a numeric value between 0 and 1 is entered into the cell, it will be the value used, regardless of the cell color. The calculator re-colors cells with numeric values in them so that they match the color whose representative value is largest and less than or equal to the numeric value in the cell. So, if the cell in the top-left corner contained the value 0.55 , the cell would be recolored green (Medium) while retaining the numeric value to be used in the calculations. If cells contain any text other than a number between 0 and 1 , the cell color sets the value.

Figure 4.8. Baseline and Option Assessment for Doctrine Table

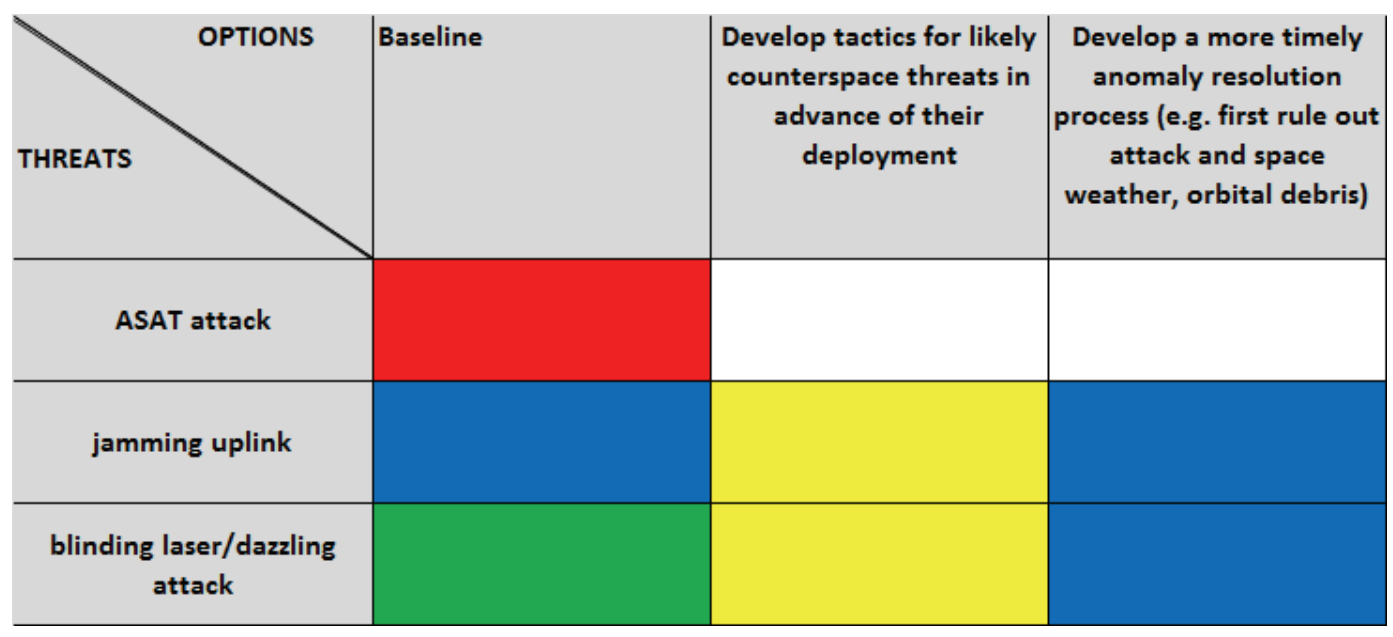




\section{Output Sheets (green tabs)}

\section{Control Panel}

As shown in Figure 4.9, the outputs on the Control Panel sheet give the element resilience for each portfolio (including the baseline), both influenced and uninfluenced, as well as the overall resilience by posture. The values are color coded using the same color scheme as the color key in the Baseline Weights table. The cost of each portfolio is given as the final row and is used in the Cost Resilience Chart sheet, described momentarily.

Figure 4.9. Control Panel Outputs

\begin{tabular}{|c|c|c|c|c|c|c|c|}
\hline \multicolumn{8}{|l|}{ Output } \\
\hline Uninfluenced Resil. & Baseline & Everything & All Doctrine & All Organization & All Training & All Personnel & All Facilities \\
\hline Doctrine & 0.45 & 0.65 & 0.65 & 0.45 & 0.45 & 0.45 & 0.45 \\
\hline Organization & 0.33 & 0.85 & 0.33 & 0.85 & 0.33 & 0.33 & 0.33 \\
\hline Training & 0.17 & 0.72 & 0.17 & 0.17 & 0.72 & 0.17 & 0.17 \\
\hline Personnel & 0.25 & 0.69 & 0.25 & 0.25 & 0.25 & 0.69 & 0.25 \\
\hline Facilities & 1.00 & 1.00 & 1.00 & 1.00 & 1.00 & 1.00 & 1.00 \\
\hline Influenced Resil. & Baseline & Everything & All Doctrine & All Organization & All Training & All Personnel & All Facilities \\
\hline Doctrine & 0.45 & 0.65 & 0.65 & 0.45 & 0.45 & 0.45 & 0.45 \\
\hline Organization & 0.33 & 0.85 & 0.33 & 0.85 & 0.33 & 0.34 & 0.33 \\
\hline Training & 0.23 & 0.71 & 0.27 & 0.27 & 0.63 & 0.23 & 0.23 \\
\hline Personnel & 0.23 & 0.71 & 0.23 & 0.26 & 0.40 & 0.51 & 0.23 \\
\hline Facilities & 0.86 & 0.97 & 0.86 & 0.96 & 0.86 & 0.87 & 0.86 \\
\hline Overall Resil. & Baseline & Everything & All Doctrine & All Organization & All Training & All Personnel & All Facilities \\
\hline Day-to-Day & 0.47 & 0.80 & 0.52 & 0.63 & 0.51 & 0.54 & 0.47 \\
\hline Crisis* & 0.43 & 0.78 & 0.46 & 0.52 & 0.52 & 0.57 & 0.43 \\
\hline Portfolio Cost & & 44. & 2.05 & 12.25 & 14.05 & 11.05 & \\
\hline
\end{tabular}




\section{Results Chart}

Figure 4.10 has two sets of bar charts: the uninfluenced resilience for each element and portfolio, and the posture-specific overall resilience values for each portfolio, which are weighted sums of the influenced resiliencies for each element.

Figure 4.10. Results Chart

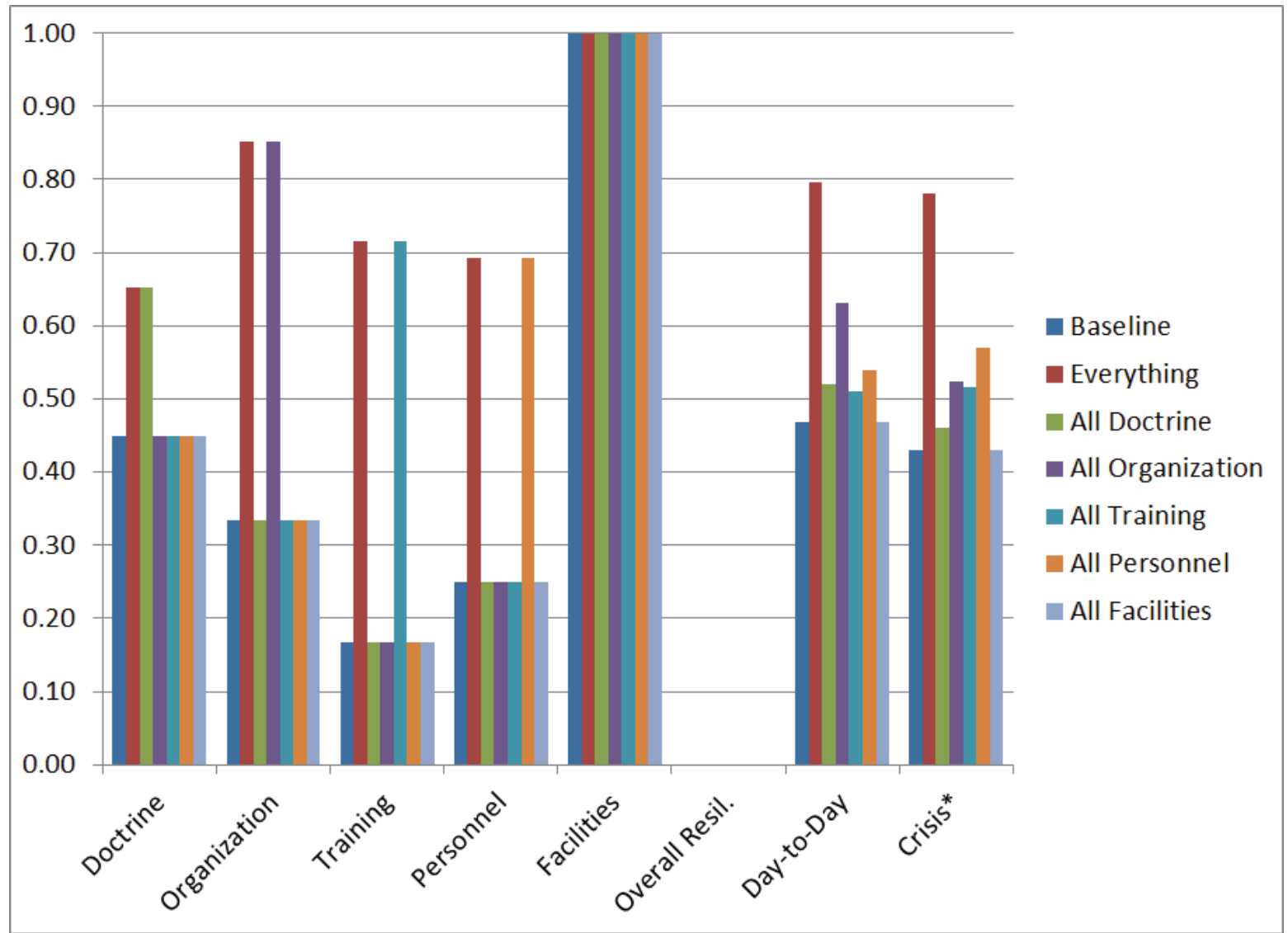




\section{Cost Resilience Chart}

Figure 4.11 is a scatterplot of portfolio cost versus overall resilience for the Crisis posture.

Figure 4.11. Cost Resilience Chart

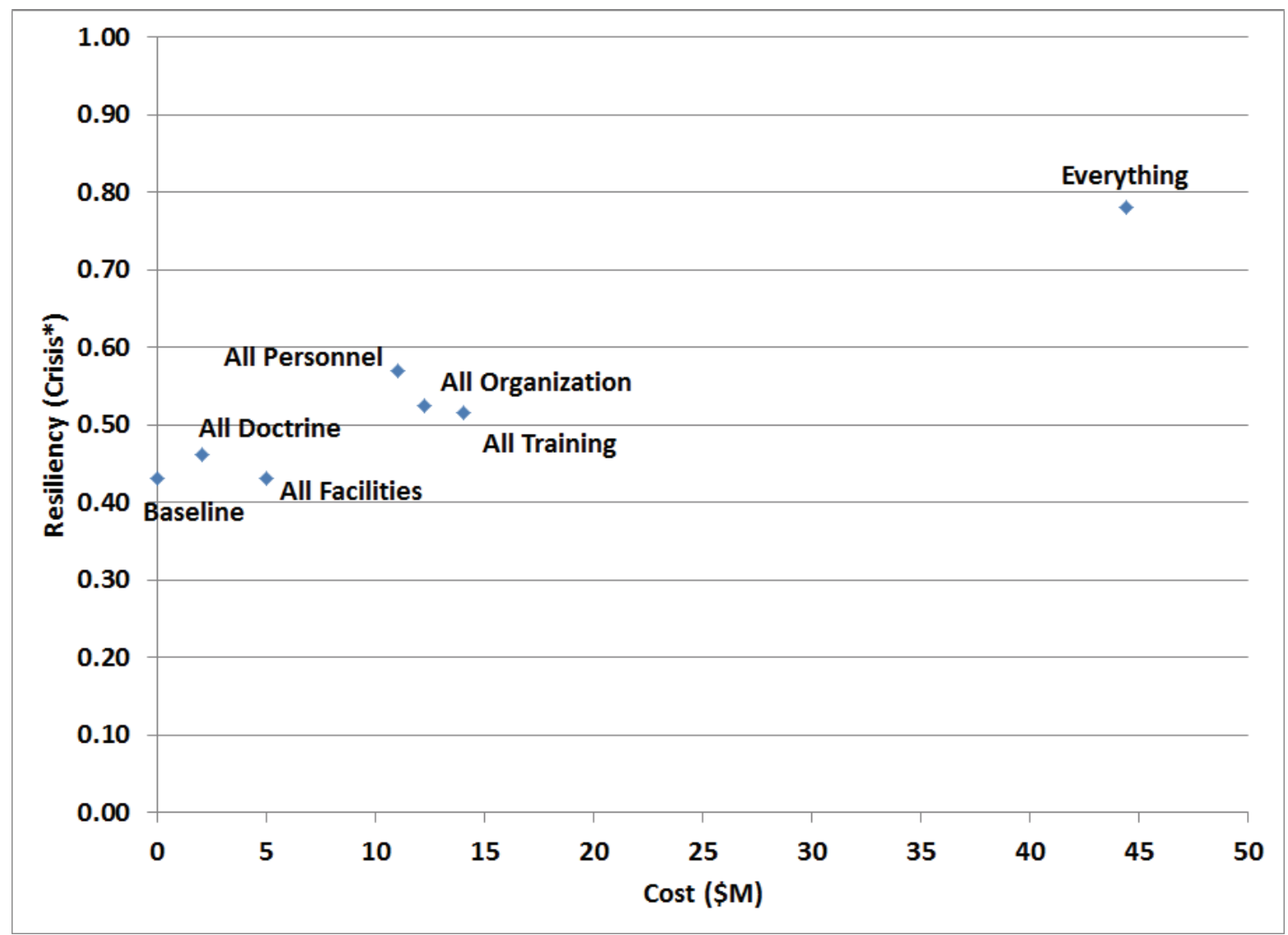

\section{Marginal Analysis (MA), Single Step MA Plot, Double Step MA Plot}

On the Marginal Analysis (MA) sheet is the Run Marginals button. If the button is pressed, the user can select an initial portfolio from which marginal analysis will be performed. In addition, the user can specify whether insertions and/or deletions from the portfolio can be considered, as well as the posture-specific overall resilience value that should be used for comparing portfolios. The tool then considers all portfolios that consist of the initial portfolio plus one or two insertions or deletions of options (as specified by the user) and ranks them by the change to the specified overall resilience value. The portfolios with one and two option changes are in separate tables, and each table also notes the cost deltas as well as deltas in ease of implementation. The Single Step MA Plot and Double Step MA Plot sheets have three-dimensional scatter plots with cost and ease of implementation deltas as the $\mathrm{x}$ - and $\mathrm{y}$-axis, and the resilience delta as the z-axis. A sample three-dimensional scatter plot result from the marginal analysis is shown in Figure 4.12. 
Figure 4.12. Sample Marginal Analysis 3-D Scatter Plot

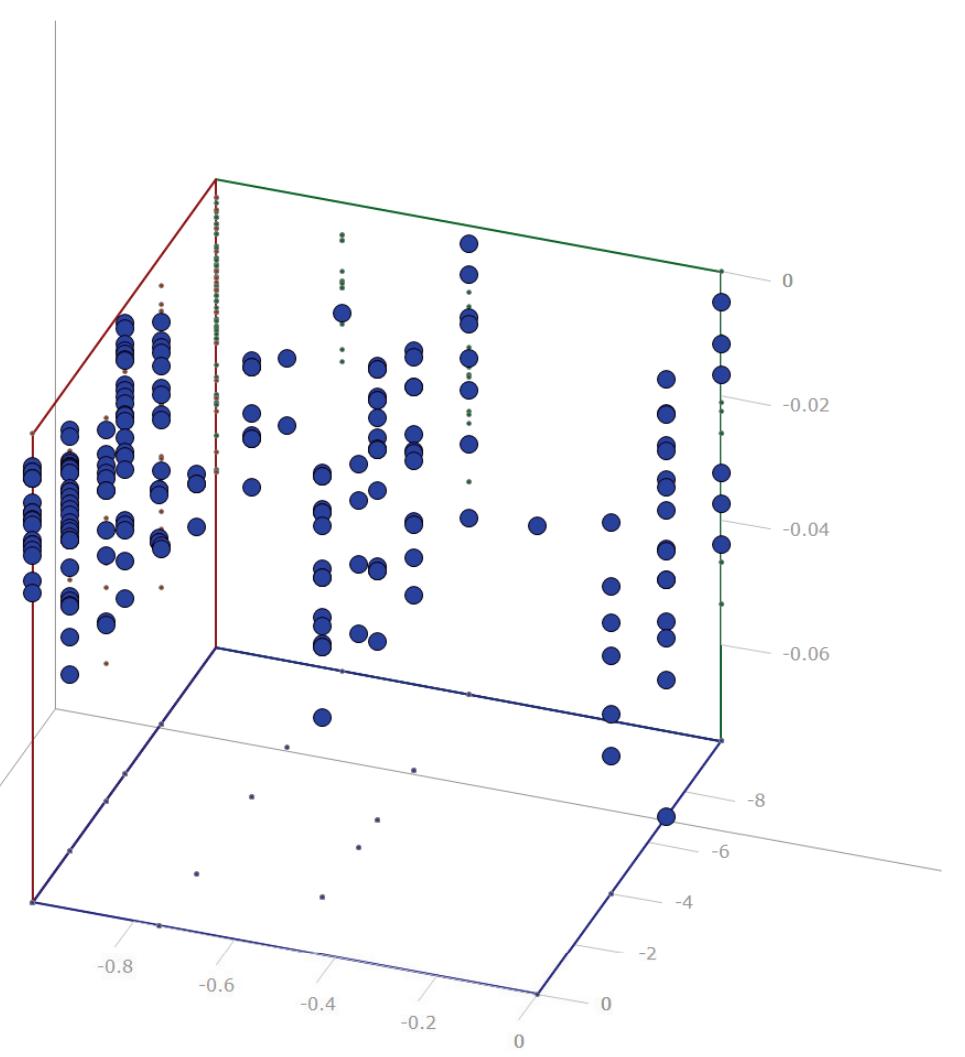

